\title{
An Intervention With Michigan-Grown Wheat in Healthy Adult Humans to Determine Effect on Gut Microbiota: Protocol for a Crossover Trial
}

Gigi A Kinney, BS; Eliot N Haddad; Linda S Garrow, PhD; Perry K W Ng, PhD; Sarah S Comstock, PhD

Department of Food Science \& Human Nutrition, Michigan State University, East Lansing, MI, United States

\section{Corresponding Author:}

Sarah S Comstock, $\mathrm{PhD}$

Department of Food Science \& Human Nutrition

Michigan State University

204 Trout Food Science Bldg

469 Wilson Rd

East Lansing, MI, 48824

United States

Phone: 15173533415

Email: comsto37@msu.edu

\section{Abstract}

Background: Daily fiber intake can increase the diversity of the human gut microbiota as well as the abundance of beneficial microbes and their metabolites. Whole-grain wheat is high in fiber.

Objective: This manuscript presents a study protocol designed to understand the effects of different types of wheat on gastrointestinal tract microbes.

Methods: Human adults will consume crackers made from three types of wheat flour (refined soft white wheat, whole-grain soft white wheat, and whole-grain soft red wheat). In this study, participants will alternate between crackers made from refined soft white wheat flour to those made from whole-grain soft white wheat and whole-grain soft red wheat flour. Survey and stool sample collection will occur after 7-day treatment periods. We will assess how wheat consumption affects gastrointestinal bacteria by sequencing the V4 region of $16 \mathrm{~S}$ rRNA gene amplicons and the inflammatory state of participants' intestines using enzyme-linked immunosorbent assays. The butyrate production capacity of the gut microbiota will be determined by targeted quantitative real-time polymerase chain reaction.

Results: We will report the treatment effects on alpha and beta diversity of the microbiota and taxa-specific differences. Microbiota results will be analyzed using the vegan package in R. Butyrate production capacity and biomarkers of intestinal inflammation will be analyzed using parametric statistical methods such as analysis of variance or linear regression. We expect whole wheat intake to increase butyrate production capacity, bacterial alpha diversity, and abundance of bacterial taxa responsive to phenolic compounds. Soft red wheat is also expected to decrease the concentration of inflammatory biomarkers in the stool of participants.

Conclusions: This protocol describes the methods to be used in a study on the impact of wheat types on the human gastrointestinal microbiota and biomarkers of intestinal inflammation. The analysis of intestinal responses to the consumption of two types of whole wheat will expand our understanding of how specific foods affect health-associated outcomes.

International Registered Report Identifier (IRRID)： DERR1-10.2196/29046

(JMIR Res Protoc 2021;10(10):e29046) doi: $\underline{10.2196 / 29046}$

\section{KEYWORDS}

fiber; microbiota; whole grain; wheat; butyrate; calprotectin; lipocalin-2 


\section{Introduction}

\section{Background}

An individual's gut microbial community is colonized by trillions of microorganisms [1]. These microorganisms interact with other cells, influencing important metabolic and immune functions. In this way, the gut microbiota can benefit the host, offering protection from pathogens and supporting immune regulation [2]. However, a dysbiotic gut microbiota is linked to disturbances in metabolic and biological processes, leading to a variety of chronic diseases as well as cancers [3]. Individuals with reduced bacterial richness are characterized by phenotypes such as increased adiposity and insulin resistance [3].

Dietary intake is strongly associated with the composition of the gut microbiota [4-9]. This effect of diet on the gut bacterial community can occur within days, quickly switching among functional profiles characteristic of different diets, and thereby making food intake an important factor for managing the gut microbiota $[5,10]$. The Western diet is characterized by foods low in fiber and high in fat and refined sugars and carbohydrates [11]. The Western dietary pattern results in a gut microbiota characterized by decreased bacterial diversity with specific losses of important microbes such as Bifidobacterium spp., Lactobacillus spp., and Bacteroidetes [12-15].

As ultraprocessed foods have become a common component of the Western diet, resulting in a loss of whole grains and fiber, the gut microbial composition has become enriched with proinflammatory microbes that correlate with metabolic risk factors and which contribute to noncommunicable chronic diseases such as obesity and type 2 diabetes [14,16,17]. Consumption of whole grains, especially when used as a replacement for refined grains, improves the gut microbiota and is inversely associated with diseases characterized by a gastrointestinal microbial community in dysbiosis [18]. Whole grains have a prebiotic effect on the gut and restore diversity [12]. Prebiotics are compounds known to support the growth of beneficial intestinal microbes [19]. Bifidobacteria and lactobacilli respond positively to increased consumption of whole grains, as observed in a diet intervention study by Costabile et al [12]. Therefore, whole grain consumption may counteract the inhibitory effects of the modern Western diet on these bacterial genera $[12,20]$ and, thus, may be one method to restore gastrointestinal microbiota diversity.

Grains are a staple of the Western diet; however, grains exist in many forms. Thus, it is important to consider the types of grains being consumed [21,22]. The 2015 and 2020 United States Department of Agriculture dietary guidelines for Americans recommended that half of all grains come from whole grains; nevertheless, refined grains are a trademark of the typical Western diet [14,23]. Compared with the consumption of whole grains, consumption of refined grains is associated with a higher risk of chronic disease. In rodent models where the animals are inoculated with human microbiota, low dietary intake of microbiota-accessible carbohydrates for several generations caused reduced microbial diversity [7].
Similarly, in humans, differences in the gut microbiota have been observed among different geographic groups consuming their culturally habitual diets [7,24]. Thus, over subsequent generations, refined grain intake can compound lost intestinal diversity and obliterate some taxa, most specifically Bacteroidales and Clostridiales [7]. Furthermore, the addition of microbiota-accessible carbohydrates to the murine diet suppressed a clinically important intestinal pathogen, Clostridium difficile [25]. Recent research has focused on replacing processed foods with whole foods to prevent this loss in microbial diversity and support gastrointestinal health $[12,13]$.

Whole grains are rich in carbohydrates accessible to the gut microbiota, which bacteria can use for food and energy [26]. Consequently, adding whole grains to the diet leads to increased gut fermentation [15]. This process produces short-chain fatty acids, notably butyrate, an important anti-inflammatory and antioxidant molecule [15]. Diets rich in fiber have been positively associated with the presence of bifidobacteria and other lactic acid-producing bacteria and are associated with a shift toward long-term maintenance of metabolic and immune health [15]. Whole-grain wheat is a good source of fiber. Thus, increasing whole-grain wheat intake increases fiber intake, leading to a more diverse microbiome that not only contains the beneficial microbes themselves but also contains their metabolites [27].

Additional components of whole-grain wheat that convey health benefits are polyphenols [28]. Polyphenols act as antioxidants and prebiotics in the gut and, as such, interact with the gut microbial community affecting its composition [29]. When compared with the consumption of refined wheat, consumption of whole wheat increases the absorption of phytochemicals and the subsequent excretion of fecal ferulic acid, a polyphenol metabolite $[13,30]$. An increase in the availability of fecal ferulic acid through the feeding of whole grains has been associated with a significant increase in Bacteroidetes in the gut $[13,20]$. Thus, the positive relationship between whole grain ferulic acid and certain taxa of the gut microbiota is proposed as a possible mechanism for the alleviation of gut inflammation [13]. As different types of wheat have different polyphenolic content, it is important to understand how they differ in their relationship with the gut microbiota.

\section{Objectives}

To fully understand the impact of whole-wheat products on humans, we must understand the effects of different types of wheat (ie, white vs red or hard vs soft) on human gastrointestinal tract microbes. However, previous studies have ignored these differences in wheat types. Therefore, we describe a protocol in which we will feed human adults crackers made from three different types of wheat flours and assess how cracker consumption affects (1) the gastrointestinal microbial communities and (2) the inflammatory state of the intestines. We hypothesize that whole-grain soft white wheat flour will promote different microbes compared with whole-grain soft red wheat flour. In addition, we expect that the whole-grain soft red wheat treatment will result in decreased intestinal inflammation compared with the refined white wheat flour treatment. The successful completion of the proposed research will improve 
our understanding of the unique effects of different types of wheat on the human gut microbiota and the inflammatory state of the gastrointestinal tract.

\section{Methods}

\section{Design}

This wheat intervention study will characterize the variable response of gut bacteria to supplementation in adult humans. Treatments will include (1) refined soft white wheat flour, (2) bran-containing whole-wheat flour of Michigan soft white wheat, or (3) bran-containing whole-wheat flour of Michigan soft red wheat. All 3 flour samples will be provided by King Milling Company (Lowell, Michigan). Each of the two whole-wheat interventions will be administered over a 1-week period, with a baseline week (refined soft white wheat flour) before the intervention begins and a washout week (refined soft white wheat flour) between the two test periods (Figure 1). Wheat flour will be administered to participants in the form of wheat crackers. The nutrient composition of the wheat crackers is provided (Table 1). During each of the two test periods, 80 $\mathrm{g}$ of crackers made from whole-grain soft white wheat flour or whole-grain soft red wheat flour will provide each participant with approximately $10.7 \mathrm{~g}$ of total dietary fiber per day (Table 1). At the end of each 1-week treatment period, a stool sample as well as answers to a health and fiber intake questionnaire, will be collected from each participant. A total of 4 stool samples will be collected from each participant over the course of the study. Microbiome samples will be aliquoted and stored at $-80^{\circ} \mathrm{C}$ until analysis.

Figure 1. Overview of study design. ELISA: enzyme-linked immunosorbent assay; PCR: polymerase chain reaction.

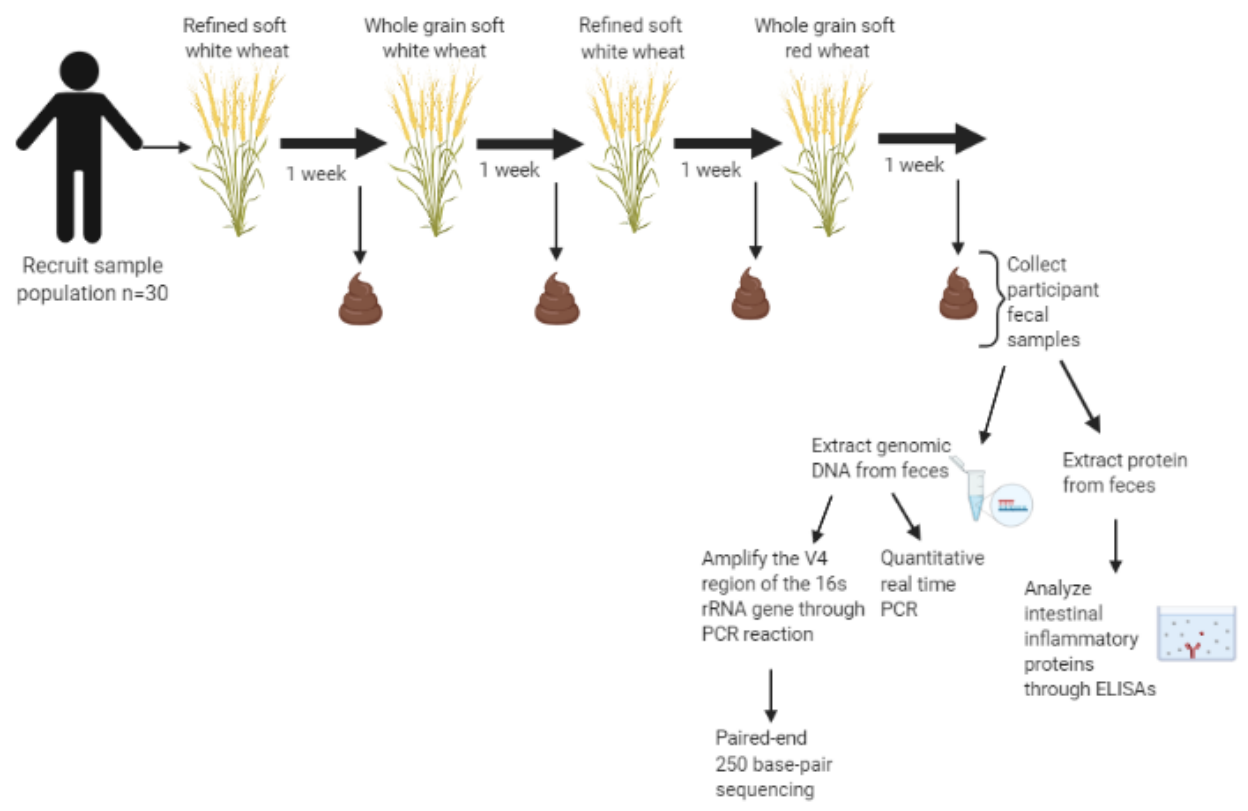


Table 1. Nutrient composition of test crackers.

\begin{tabular}{llll}
\hline Nutrient composition & $\begin{array}{l}80 \text {-g portion of crackers } \\
\text { Refined soft white wheat flour } \\
\text { crackers }\end{array}$ & $\begin{array}{l}\text { Whole-grain soft white wheat flour } \\
\text { crackers }\end{array}$ & $\begin{array}{l}\text { Whole-grain soft red wheat flour } \\
\text { crackers }\end{array}$ \\
\hline $\begin{array}{l}\text { Calories (kcal) } \\
\text { Fat (g) }\end{array}$ & 313 & 298 & 306 \\
$\quad 6.44$ & 7.16 & 8.00 \\
$\quad$ Saturated fat & 1.68 & 1.82 & 2.08 \\
MUFA $^{\text {a }}$ & 1.26 & 1.41 & 1.59 \\
PUFA $^{\text {b }}$ & 3.16 & 3.54 & 3.92 \\
$\quad \begin{array}{l}\text { Trans fat } \\
\text { Protein (g) }\end{array}$ & 0.058 & 0.071 & 0.082 \\
Carbohydrates (g) & 7.15 & 9.10 & 9.35 \\
$\quad$ Total dietary fiber & 3.99 & & 10.72 \\
$\quad$ Insoluble fiber & 1.54 & 10.72 & 7.35 \\
$\quad$ Soluble fiber & 2.45 & 7.54 & 3.37 \\
Sodium (mg) & 439 & 3.18 & 454 \\
\hline
\end{tabular}

${ }^{a}$ MUFA: monounsaturated fatty acids.

${ }^{\mathrm{b}}$ PUFA: polyunsaturated fatty acids.

\section{Setting and Participant Recruitment}

This study will be conducted during the summer in East Lansing, Michigan, on the campus of Michigan State University and will enroll 30 adults. Subjects will be recruited via flyers hung in buildings around the Michigan State University campus as well as through the Michigan State University-paid research pool [31]. To be included in the study, participants must be aged between 18 and 55 years as the gut microbiota matures by adulthood and remains stable throughout [1]. Participants must also have bowel movements at least once every 3 days, be willing to eat wheat crackers, and be available for weekly lab visits. Participants will be excluded if they take any nonsteroidal anti-inflammatory drugs, antacids, proton pump inhibitors, nutritional supplements, or multivitamins daily; have taken any antibiotics in the 2 weeks before the study; have gastrointestinal issues or diabetes; are pregnant; are following any special diet; or have food allergies. Participants will be provided with a US $\$ 50$ cash incentive upon completion of the dietary intervention. All participants will provide written informed consent.

\section{Dietary Intervention}

The dietary intervention will consist of a 4-week period of wheat consumption in the form of wheat crackers. Each week, participants will be given 7 bags of crackers ( 1 bag for each day of the week), containing approximately $80 \mathrm{~g}$ of baked crackers per bag, to be eaten throughout the following week. Each $80 \mathrm{~g}$ cracker allotment will provide approximately $10.7 \mathrm{~g}$ of total dietary fiber for crackers made from either whole-grain soft white flour or whole-grain soft red flour. The nutrients and calories of the $80 \mathrm{~g}$ cracker allotment consumed per day are listed in Table 1.
Crackers for each treatment week will be made in bulk to yield 260 daily portions (7 portions per participant plus extra), with approximately $80 \mathrm{~g}$ of baked crackers per daily portion per person. The cracker was formulated as $100 \mathrm{~g}$ flour (approximately 13\% moisture), $1.5 \mathrm{~g}$ of iodized salt, $2 \mathrm{~g}$ of sugar, $6 \mathrm{~g}$ of vegetable shortening, and 49 to $50 \mathrm{~g}$ of tap water. The proportions of flour, salt, and sugar, according to the formulation stated above, will be added into the bowl of a Hobart mixer (model A-200) and whisked to combine the dry ingredients. Fat will be added to the dry ingredients and mixed until the fat particles are reduced in size to approximately 1 to $2 \mathrm{~mm}$. Water will then be added and mixed until a firm dough forms. The amount of water (approximately $48 \mathrm{~g}$ ) will need to be adjusted to ensure that all flour is fully hydrated. The dough will then be portioned by dividing it into $127 \mathrm{~g}$ aliquots based on the expected yield of $80 \mathrm{~g}$ of baked crackers per $127 \mathrm{~g}$ of dough (determined in preliminary testing). Each $127 \mathrm{~g}$ portion will be flattened between two pieces of parchment paper using a dough sheeter set to $3 / 32$ inch. The top sheet of the parchment paper will be removed, and the dough will be cut into approximately 1- to 2-cm-wide strips. Crackers from each portion of dough will be baked in a carousel oven for approximately 11 to 12 minutes at $400{ }^{\circ} \mathrm{F}$ until browned. Crackers will be cooled on a rack on the workbench before being placed into individual resealable portion bags labeled day 1 to day 7; then, 7 bags will be placed in one larger bag to be distributed to each participant.

As this study involves adding approximately 300 calories of carbohydrate-containing food to the daily diet, participants will receive flyers (Figure 2) informing them how to incorporate the crackers into their diets by replacing everyday dietary items such as cereals and bread with the test crackers. This will prevent or minimize participants' weight gain. 
Figure 2. Flyer to be distributed to participants providing calories in common serving sizes of typical carbohydrate-containing foods.

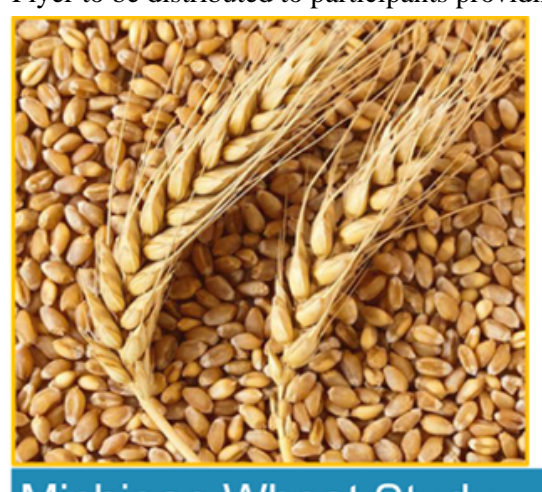

Michigan Wheat Study

The crackers being consumed as a part of this study will be about 500 calories per day. As such, they should substitute your carb intake at each meal instead of adding to your usual caloric intake.

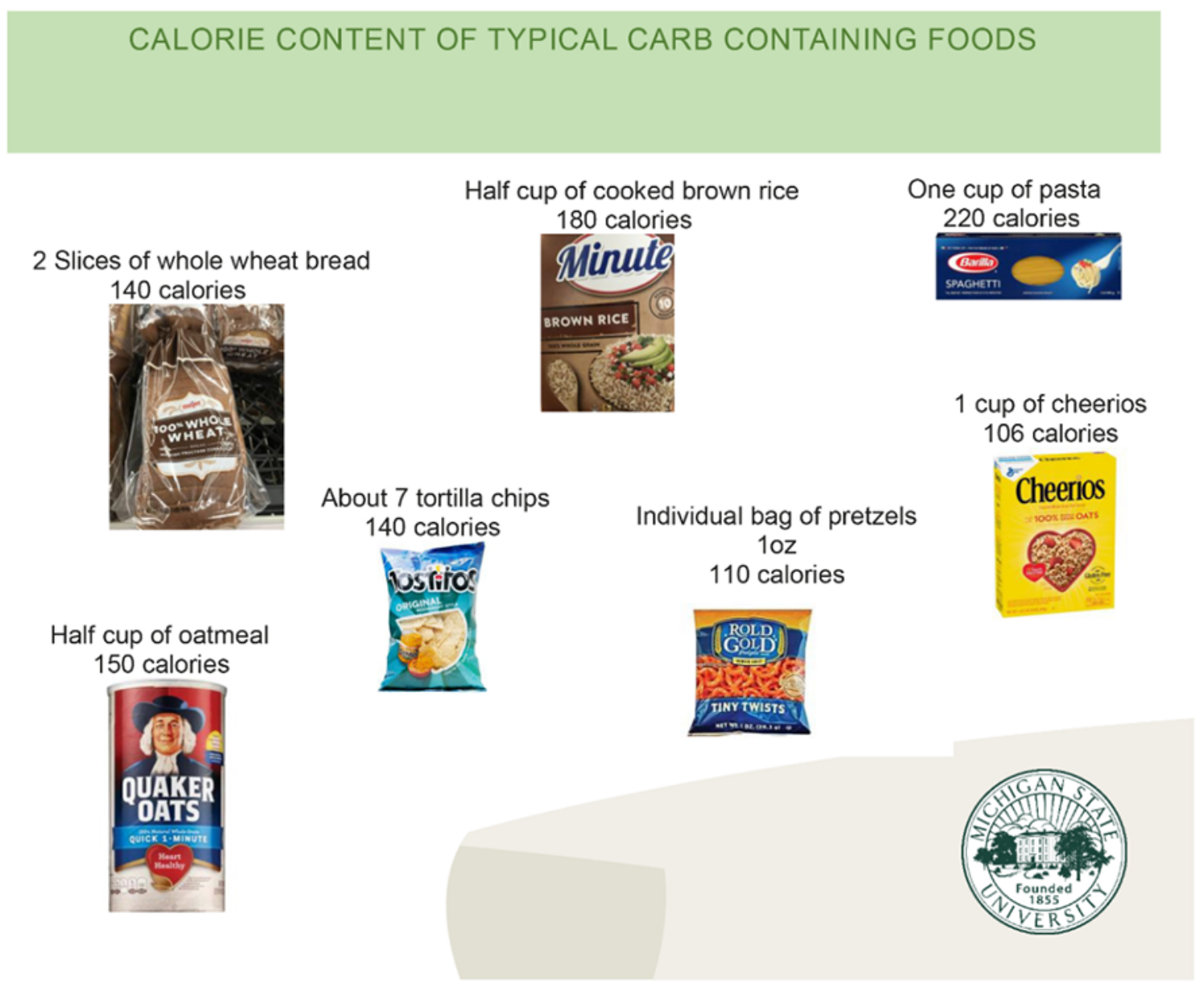

\section{Outcomes}

\section{Overview}

At the conclusion of each week, stool samples will be collected for analysis. The primary outcome measure will be the alpha diversity of the gut microbiota. This will be measured using the sequencing data obtained from the participants' stool samples after DNA extraction and polymerase chain reaction (PCR) amplification of the V4 region of the 16S rRNA gene. The secondary outcome measure will be biomarkers of gastrointestinal inflammation, as measured by protein concentrations of calprotectin and lipocalin- 2 in protein extracts of the stool samples. Furthermore, the microbiota beta diversity, abundance of Bifidobacterium and Lactobacillus, and butyrate production capacity of the gut microbiota will be assessed after each week of treatment. The abundance of Bifidobacterium and Lactobacillus will be determined from the sequencing results. The butyrate production capacity will be determined by 
quantitative real-time PCR assays targeting the bacterial butyrate kinase and butyrate transferase genes [32].

\section{Other Measurements}

Background characteristics of the study participants will be recorded during recruitment when each participant will complete a short questionnaire. In addition, current weight, health status, 24-hour dietary intake, and water source will be collected each week along with a fiber intake questionnaire (described below) recording the amount of fiber-containing foods consumed throughout the week. A 24-hour recall will be implemented as this has been previously reported to supply sufficient information to interpret microbiota data from participants' fecal samples [33]. Participants will self-report their 24-hour dietary intake by free response to the question "What did you eat and drink in the past day? (Please give as much detail as possible, including the estimated amounts)."

\section{Data Analysis}

\section{Diet Analyses}

\section{Overview}

Individual diet diversity scores will be calculated for each participant at each time point. The use of the diet diversity score provides a more general measure of the variety of dietary intake than specific food consumption data. This scoring system counts the number of food groups consumed by an individual. Data will be supplied based on the 24-hour intake data provided in response to this prompt, "What did you eat and drink in the past day? (Please give as much detail as possible, including the estimated amounts.)" as well as their answers to a checklist of 34 food and supplement items where participants are prompted to "Place an ' $x$ ' in the box next to anything that you ate in the past 24 hours." The food checklist was designed to capture the intake of the foods listed in the diet diversity scoring tool document of the Food and Agriculture Organization of the United Nations [34]. Dietary diversity score will be assessed as described by the Food and Agriculture Organization of the United Nations [34].

\section{Fiber Intake Analysis}

The PhenX fiber intake protocol will be used to assess additional dietary fiber intake [35]. Each week, participants will receive a screener (PhenX protocol 50601) asking them to report how often they consumed different types of fiber-containing foods (ie, cereal, vegetables, and beans). Participants will record how often they consumed a portion of food-never, less than once a day, once a day, twice a day, three times a day, four times a day, or five or more times per day. A score will be assigned to each participant at each time point using the scoring methods provided by the PhenX protocol. This score will be used to account for the fiber in the diet that is not from the test crackers.

\section{Microbiota Analyses}

Stool samples will be extracted, prepared for sequencing of the $16 \mathrm{~S}$ rRNA gene, and sequenced as described in references [36-38].

\section{Butyrate Gene Analyses}

Quantitative real-time PCR will be performed on the genomic DNA from each sample to determine the levels of butyryl-CoA: acetate CoA-transferase (but) and butyrate kinase (buk). Primer sets, But_RosEub, But_G.prausn, and Buk, previously designed by Vital et al [32], will be used. All genomic DNA samples will be diluted to 2.5 to $5 \mathrm{ng} / \mu \mathrm{L}$. In a 96-well plate, genomic standards at concentrations of $10^{2}$ to $10^{7}$ will be used to create a standard curve. All wells will be filled with 7.5 $\mu \mathrm{L}$ SYBR

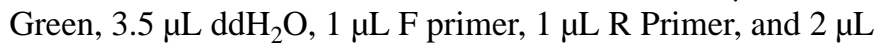
template. The thermocycling program to be performed is as follows: 2 minutes at $50^{\circ} \mathrm{C}, 10$ minutes at $95^{\circ} \mathrm{C}, 45$ seconds at $95^{\circ} \mathrm{C}, 45$ seconds at annealing temperature for the specific primer, and 45 seconds at $72^{\circ} \mathrm{C}$ for 40 cycles. A one-way repeated-measures analysis of variance (ANOVA) will be performed on each set of data to compare the relative abundance and presence of the following butyrate synthesizers: Faecalibacterium prausnitzii, Eubacteria spp., Roseburia spp., and Clostridium acetobutylicum.

\section{Intestinal Inflammatory Protein Analyses}

Proteins will be extracted from the stool samples. The extraction buffers for lipocalin (catalog number 30757) and calprotectin (catalog number 30473) will be purchased from Epitope Diagnostics, Inc. First, the fecal samples will be aliquoted and stored at $-80^{\circ} \mathrm{C}$ until protein extractions are performed. Then, approximately $100 \mathrm{mg}$ of fecal material will be aliquoted into a conical tube, and the exact weight of the sample will be recorded. Each sample will be extracted separately with each of the two extraction buffers. Using a serological pipette, $4 \mathrm{~mL}$ of extraction buffer per $100 \mathrm{mg}$ of stool will be aliquoted into a conical tube for each sample. Each tube will be gently vortexed and incubated at room temperature on an orbital shaker for 30 minutes. The protein extracts will then be aliquoted into microfuge tubes and stored at $-80^{\circ} \mathrm{C}$ until ELISAs (enzyme-linked immunosorbent assays) are performed. The ELISA kits will be purchased from R\&D Systems (a Bio-Techne brand) for human calprotectin (S100A8/S100A9; DS8900) and human lipocalin-2 (neutrophil gelatinase-associated lipocalin; DLCN20). Fecal extracts will be diluted at $1: 25$ or $1: 100$ in sample diluent for calprotectin assays and 1:20 or 1:100 in sample diluent for neutrophil gelatinase-associated lipocalin assays.

\section{Statistical Analyses}

Statistical analysis of differences between pre- and posttests will be assessed using ANOVA or Friedman Wilcoxon rank-sum tests [39]. Multivariate statistics will be performed using R ( R Foundation for Statistical Computing), a free statistical software program. To compare the alpha diversity of the microbial communities, Chao1 (a measure of richness), inverse Simpson (a measure of richness and evenness, with emphasis on evenness), and Shannon diversity (a measure of richness and evenness, with emphasis on richness) will be calculated in $\mathrm{R}$ using the vegan package [40]. ANOVA and Wilcoxon signed-rank test or Friedman test with post hoc comparisons will be used to compare alpha diversity across treatment categories after intervention [41]. For beta diversity, Bray-Curtis and Sorenson distances will be used with principal coordinates 
analysis ordination to produce plots of the distances between samples. Differences in beta diversity between time points will be determined using permutational multivariate ANOVA (PERMANOVA) via the adonis function in the vegan package, and differences in group dispersion will be determined using PERMDISP [40]. PERMANOVA may also be used to determine the relationship between the distance metrics and wheat variety, as well as other variables. Metastats (a function of the mothur software package) will be performed on the subsampled abundance data to test for significant differences in operational taxonomic unit abundance between groups [42]. Changes in taxa (both genus and phylum level) $>1 \%$ average relative abundance will be determined across time points using the Friedman test with post hoc comparisons. Where appropriate, the negative binomial and zero-inflated mixed models in the $\mathrm{R}$ package will be used to test for differences in taxa abundance over time [43].

Enterotypes will be manually assigned based on clustering within quadrants in a Bray-Curtis principal coordinates analysis plot overlaid with the most abundant taxa driving community differences, as in Wu et al [4], using the envfit function in the vegan package. Significant differences between enterotypes will be determined using ANOVA for parametric data and the Kruskal-Wallis test for nonparametric data. Differences between time points within each enterotype will be determined using the Friedman test with post hoc comparisons.

\section{Response Analysis}

If only a subset of participants is found to respond to the treatment, response groups will be determined by an individual's change in alpha diversity metrics across the treatments. A participant will be considered a positive responder if alpha diversity (either Chao1, Shannon, or inverse Simpson) is greater at time points $\mathrm{B}$ and $\mathrm{D}$ (whole wheat) than at both $\mathrm{A}$ and $\mathrm{C}$ (refined white wheat). However, if this change is not observed, participants will be considered nonresponders. After post hoc assignment of response groups, differences in overall alpha diversity between positive responder and nonresponder groups will be tested with ANOVA (if parametric) or Wilcoxon ranked-sum (if nonparametric). The normality of data will be determined using the Shapiro-Wilk test. Differences will be tested within each time point. Beta diversity differences between response groups will be determined at each time point using PERMANOVA and PERMDISP. Continuous demographic variables (age, BMI, and fiber intake) will be compared with a two-tailed $t$ test if parametric and a Wilcoxon rank-sum test if nonparametric, with normality confirmed using the Shapiro-Wilk test. The Fisher exact test will be used to determine the independence of sex, smoking exposure, and race regarding response to treatment. Differences in genera present at $>1 \%$ average relative abundance will be tested between response groups using a negative binomial model in the MASS package [44].

\section{Results}

The study procedures were approved by the Michigan State University institutional review board (IRB \#00002638) in spring
2019. Sample collection occurred in summer 2019. The results of this research are expected to be published in late 2021 .

\section{Discussion}

\section{Impact}

The primary aim of this study is to measure the alpha diversity of gut microbiota following each week of cracker treatment to determine whether whole-wheat consumption increases alpha diversity. Additional aims are to measure the levels of gastrointestinal inflammation as well as Bifidobacterium, Lactobacillus, and butyrate-producing bacteria that are present following each treatment. These analyses will elucidate how different types of wheat may affect the gastrointestinal tract microbiota.

Only recently have we begun to understand the mechanism by which whole grains promote health $[12,16,21,45]$. Various microbes and metabolites have been hypothesized to decrease inflammation; however, much is still unknown [14]. Our aim - to measure how microbial diversity and levels of certain bacteria are affected by whole-wheat intake-will elucidate the potential mechanisms by which whole grains affect health. In addition, little is known about the effects of different types of wheat (eg, white vs red) on the gut microbiota. Specific wheat types have different molecular compositions and may therefore promote different microbes [46-49]. Taking into account the effects of different types of whole wheat will allow us to understand better the food characteristics that underlie the impact of whole-wheat consumption on humans.

We anticipate that the results of this intervention study will have implications for both wheat producers and consumers. Recent trends suggest an increase in the number of consumers who avoid wheat products as part of new diets that emphasize carbohydrate reduction, despite the unclear benefits of avoidance in those without celiac disease [50]. In fact, the risks of avoiding gluten, and subsequently whole grains, include deficiency of micronutrients, fiber, and an increased consumption of refined products, which may outweigh the perceived benefits of avoiding wheat [50]. Understanding how microbes and gastrointestinal inflammation are affected by the consumption of whole-grain wheat may increase the consumption of whole-grain wheat by health-conscious consumers.

\section{Strengths and Weaknesses}

An important strength of this study is the composition of the crackers. The aim of the study is to test the effect of specific types of wheat; thus, it is important to note that we have created a cracker formulation that is composed almost entirely of the wheat of interest with few additional ingredients. The simple recipe we have developed for the crackers will improve confidence that the differences observed in the microbial community and inflammatory biomarkers are owing to the consumption of the wheat in the study crackers rather than a different ingredient in the treatment food. The quick turnaround from the cracker intake to sample collection also helps strengthen the study. Stool samples will be collected on the final day of each week's cracker intake, ensuring that little time has elapsed between the last cracker intake and stool sample 
collection. This is important for microbiota analyses as the temporal intake of food is tightly associated with microbial composition [51]. In addition, we will allow sufficient time to pass between each intervention through the use of a washout period. Johnson et al [33] described a minimum 3- to 5-day period between crossing-over diets to allow the microbiome to return to baseline. The crossover design of this study will allow us to perform within-person comparisons, placing less emphasis on interindividual differences in the gut microbiome [33].

A potential limitation of our study may be participant retention. Participants will be expected to consume approximately $80 \mathrm{~g}$ of crackers every day for 4 weeks, so it is important that they enjoy the taste of the crackers to ensure their compliance and continuance in the study. However, the study participants may tire of the taste of the crackers. A high dropout rate could hinder our ability to detect statistically significant differences.

Whole grains alleviate dysbiosis in the gut microbiota; however, little is known about the impact of different wheat types on this phenomenon $[12,18,20]$. A 4-week wheat intervention to investigate the effect of different types of Michigan-grown wheat on the gut microbiota is described in this protocol. The results of this study will improve our understanding of the unique effects of different types of wheat on gut microbiota and on the inflammatory state of the human gastrointestinal tract.

\section{Acknowledgments}

Figure 1 was created at BioRender. This study is funded by the Michigan Soft White Wheat Endowment and Michigan State University AgBioResearch.

\section{Authors' Contributions}

SSC, LSG, and PKWN designed the study and critically revised the manuscript. SSC and PKWN wrote the proposal for the funding agency. GAK wrote the manuscript. ENH outlined the statistical analysis plan. All the authors approved the final version of the manuscript.

\section{Conflicts of Interest}

None declared.

\section{References}

1. Thursby E, Juge N. Introduction to the human gut microbiota. Biochem J 2017 May 16;474(11):1823-1836 [FREE Full text] [doi: 10.1042/BCJ20160510] [Medline: 28512250]

2. Dieterich W, Schink M, Zopf Y. Microbiota in the gastrointestinal tract. Med Sci (Basel) 2018 Dec 14;6(4):116 [FREE Full text] [doi: 10.3390/medsci6040116] [Medline: 30558253 ]

3. Ussar S, Griffin N, Bezy O, Fujisaka S, Vienberg S, Softic S, et al. Interactions between gut microbiota, host genetics and diet modulate the predisposition to obesity and metabolic syndrome. Cell Metab 2015 Sep 01;22(3):516-530 [FREE Full text] [doi: 10.1016/j.cmet.2015.07.007] [Medline: 26299453]

4. Wu GD, Chen J, Hoffmann C, Bittinger K, Chen Y, Keilbaugh SA, et al. Linking long-term dietary patterns with gut microbial enterotypes. Science 2011 Oct 07;334(6052):105-108 [FREE Full text] [doi: 10.1126/science.1208344] [Medline: 21885731]

5. David LA, Maurice CF, Carmody RN, Gootenberg DB, Button JE, Wolfe BE, et al. Diet rapidly and reproducibly alters the human gut microbiome. Nature 2014 Jan 23;505(7484):559-563 [FREE Full text] [doi: 10.1038/nature12820] [Medline: 24336217]

6. Goodrich J, Davenport E, Beaumont M, Jackson M, Knight R, Ober C, et al. Genetic determinants of the gut microbiome in UK twins. Cell Host Microbe 2016 May 11;19(5):731-743 [FREE Full text] [doi: 10.1016/j.chom.2016.04.017] [Medline: 27173935]

7. Sonnenburg ED, Smits SA, Tikhonov M, Higginbottom SK, Wingreen NS, Sonnenburg JL. Diet-induced extinctions in the gut microbiota compound over generations. Nature 2016 Jan 14;529(7585):212-215 [FREE Full text] [doi: 10.1038/nature16504] [Medline: 26762459]

8. Rothschild D, Weissbrod O, Barkan E, Kurilshikov A, Korem T, Zeevi D, et al. Environment dominates over host genetics in shaping human gut microbiota. Nature 2018 Mar 08;555(7695):210-215. [doi: 10.1038/nature25973] [Medline: 29489753]

9. Asnicar F, Berry SE, Valdes AM, Nguyen LH, Piccinno G, Drew DA, et al. Microbiome connections with host metabolism and habitual diet from 1,098 deeply phenotyped individuals. Nat Med 2021 Feb;27(2):321-332 [FREE Full text] [doi: 10.1038/s41591-020-01183-8] [Medline: $\underline{33432175]}$

10. Bibbò S, Ianiro G, Giorgio V, Scaldaferri F, Masucci L, Gasbarrini A, et al. The role of diet on gut microbiota composition. Eur Rev Med Pharmacol Sci 2016 Nov;20(22):4742-4749 [FREE Full text] [Medline: 27906427]

11. Drake I, Sonestedt E, Ericson U, Wallström P, Orho-Melander M. A Western dietary pattern is prospectively associated with cardio-metabolic traits and incidence of the metabolic syndrome. Br J Nutr 2018 May;119(10):1168-1176. [doi: 10.1017/S000711451800079X] [Medline: 29759108] 
12. Costabile A, Klinder A, Fava F, Napolitano A, Fogliano V, Leonard C, et al. Whole-grain wheat breakfast cereal has a prebiotic effect on the human gut microbiota: a double-blind, placebo-controlled, crossover study. Br J Nutr 2008 Jan;99(1):110-120. [doi: 10.1017/S0007114507793923] [Medline: 17761020 ]

13. Vitaglione P, Mennella I, Ferracane R, Rivellese AA, Giacco R, Ercolini D, et al. Whole-grain wheat consumption reduces inflammation in a randomized controlled trial on overweight and obese subjects with unhealthy dietary and lifestyle behaviors: role of polyphenols bound to cereal dietary fiber. Am J Clin Nutr 2015 Feb;101(2):251-261. [doi: 10.3945/ajcn.114.088120] [Medline: 25646321]

14. Zinöcker MK, Lindseth I. The western diet-microbiome-host interaction and its role in metabolic disease. Nutrients 2018 Mar 17;10(3):365 [FREE Full text] [doi: 10.3390/nu10030365] [Medline: 29562591]

15. Jefferson A, Adolphus K. The effects of intact cereal grain fibers, including wheat bran on the gut microbiota composition of healthy adults: a systematic review. Front Nutr 2019 Mar 29;6:33 [FREE Full text] [doi: 10.3389/fnut.2019.00033] [Medline: $\underline{\text { 30984765] }}$

16. Aune D, Norat T, Romundstad P, Vatten LJ. Whole grain and refined grain consumption and the risk of type 2 diabetes: a systematic review and dose-response meta-analysis of cohort studies. Eur J Epidemiol 2013 Nov;28(11):845-858. [doi: 10.1007/s10654-013-9852-5] [Medline: 24158434]

17. McGill C, Fulgoni VL, Devareddy L. Ten-year trends in fiber and whole grain intakes and food sources for the United States population: National Health and Nutrition Examination Survey 2001-2010. Nutrients 2015 Feb 09;7(2):1119-1130 [FREE Full text] [doi: 10.3390/nu7021119] [Medline: 25671414]

18. Vanegas SM, Meydani M, Barnett JB, Goldin B, Kane A, Rasmussen H, et al. Substituting whole grains for refined grains in a 6-wk randomized trial has a modest effect on gut microbiota and immune and inflammatory markers of healthy adults. Am J Clin Nutr 2017 Mar;105(3):635-650 [FREE Full text] [doi: 10.3945/ajcn.116.146928] [Medline: 28179226]

19. Gibson GR, Hutkins R, Sanders ME, Prescott SL, Reimer RA, Salminen SJ, et al. Expert consensus document: The International Scientific Association for Probiotics and Prebiotics (ISAPP) consensus statement on the definition and scope of prebiotics. Nat Rev Gastroenterol Hepatol 2017 Aug;14(8):491-502. [doi: 10.1038/nrgastro.2017.75] [Medline: 28611480]

20. Gong L, Cao W, Chi H, Wang J, Zhang H, Liu J, et al. Whole cereal grains and potential health effects: involvement of the gut microbiota. Food Res Int 2018 Jan;103:84-102. [doi: 10.1016/j.foodres.2017.10.025] [Medline: 29389647]

21. Aune D, Keum N, Giovannucci E, Fadnes LT, Boffetta P, Greenwood DC, et al. Whole grain consumption and risk of cardiovascular disease, cancer, and all cause and cause specific mortality: systematic review and dose-response meta-analysis of prospective studies. BMJ 2016 Jun 14;353:i2716 [FREE Full text] [doi: 10.1136/bmj.i2716] [Medline: 27301975]

22. Awika JM, Rose DJ, Simsek S. Complementary effects of cereal and pulse polyphenols and dietary fiber on chronic inflammation and gut health. Food Funct 2018 Mar 01;9(3):1389-1409 [FREE Full text] [doi: 10.1039/c7fo02011b] [Medline: 29532826]

23. Dietary guidelines for Americans 2020-2025. USDA. 2020. URL: https://www.dietaryguidelines.gov/sites/default/files/ 2020-12/Dietary_Guidelines_for_Americans_2020-2025.pdf [accessed 2021-08-26]

24. De Filippo C, Cavalieri D, Di Paola M, Ramazzotti M, Poullet JB, Massart S, et al. Impact of diet in shaping gut microbiota revealed by a comparative study in children from Europe and rural Africa. Proc Natl Acad Sci U S A 2010 Aug 17;107(33):14691-14696 [FREE Full text] [doi: 10.1073/pnas.1005963107] [Medline: 20679230]

25. Hryckowian AJ, Van Treuren W, Smits SA, Davis NM, Gardner JO, Bouley DM, et al. Microbiota-accessible carbohydrates suppress Clostridium difficile infection in a murine model. Nat Microbiol 2018 Jun;3(6):662-669 [FREE Full text] [doi: 10.1038/s41564-018-0150-6] [Medline: 29686297]

26. Singh RK, Chang H, Yan D, Lee KM, Ucmak D, Wong K, et al. Influence of diet on the gut microbiome and implications for human health. J Transl Med 2017 Apr 08;15(1):73 [FREE Full text] [doi: 10.1186/s12967-017-1175-y] [Medline: 28388917]

27. Laitinen K, Mokkala K. Overall dietary quality relates to gut microbiota diversity and abundance. Int J Mol Sci 2019 Apr 13;20(8):1835 [FREE Full text] [doi: 10.3390/ijms20081835] [Medline: 31013927]

28. Ozdal T, Sela DA, Xiao J, Boyacioglu D, Chen F, Capanoglu E. The reciprocal interactions between polyphenols and gut microbiota and effects on bioaccessibility. Nutrients 2016 Feb 06;8(2):78 [FREE Full text] [doi: 10.3390/nu8020078] [Medline: 26861391]

29. Duda-Chodak A, Tarko T, Satora P, Sroka P. Interaction of dietary compounds, especially polyphenols, with the intestinal microbiota: a review. Eur J Nutr 2015 Apr;54(3):325-341 [FRE Full text] [doi: 10.1007/s00394-015-0852-y] [Medline: $\underline{25672526]}$

30. Neacsu M, McMonagle J, Fletcher RJ, Hulshof T, Duncan SH, Scobbie L, et al. Availability and dose response of phytophenols from a wheat bran rich cereal product in healthy human volunteers. Mol Nutr Food Res 2017 Mar;61(3):-. [doi: 10.1002/mnfr.201600202] [Medline: 27356494]

31. Paid research pool. Michigan State University. URL: https://msucas-paid.sona-systems.com/Default.aspx?ReturnUrl=\%2f [accessed 2021-01-29]

32. Vital M, Penton CR, Wang Q, Young VB, Antonopoulos DA, Sogin ML, et al. A gene-targeted approach to investigate the intestinal butyrate-producing bacterial community. Microbiome 2013 Mar 04;1(1):8 [FREE Full text] [doi: 10.1186/2049-2618-1-8] [Medline: 24451334] 
33. Johnson AJ, Zheng JJ, Kang JW, Saboe A, Knights D, Zivkovic AM. A guide to diet-microbiome study design. Front Nutr 2020 Jun 12;7:79 [FREE Full text] [doi: 10.3389/fnut.2020.00079] [Medline: $\underline{\text { 32596250] }}$

34. Guidelines for measuring household and individual dietary diversity. Food and Agriculture Organization of the United Nations. URL: http://www.fao.org/3/a-i1983e.pdf [accessed 2021-08-26]

35. Protocol - fiber intake. PhenX Toolkit. URL: https://www.phenxtoolkit.org/protocols/view/50601 [accessed 2021-01-20]

36. Sugino KY, Paneth N, Comstock SS. Michigan cohorts to determine associations of maternal pre-pregnancy body mass index with pregnancy and infant gastrointestinal microbial communities: late pregnancy and early infancy. PLoS One 2019 Mar 18;14(3):e0213733 [FREE Full text] [doi: 10.1371/journal.pone.0213733] [Medline: 30883572]

37. Haddad EN, Sugino KY, Tucker RM, Comstock SS. Gut enterotypes are stable during Bifidobacterium and Lactobacillus probiotic supplementation. J Food Sci 2020 May;85(5):1596-1604. [doi: 10.1111/1750-3841.15127] [Medline: 32267970]

38. Sugino KY, Ma T, Kerver JM, Paneth N, Comstock SS. Human milk feeding patterns at 6 months of age are a major determinant of fecal bacterial diversity in infants. J Hum Lact 2020 Sep 14:890334420957571 (forthcoming). [doi: 10.1177/0890334420957571] [Medline: 32926654]

39. Kim H. Statistical notes for clinical researchers: nonparametric statistical methods: 2 . Nonparametric methods for comparing three or more groups and repeated measures. Restor Dent Endod 2014 Nov;39(4):329-332 [FREE Full text] [doi: 10.5395/rde.2014.39.4.329] [Medline: 25383354]

40. vegan: Community Ecology Package. Cran Project. URL: https://cran.r-project.org/web/packages/vegan/index.html [accessed 2021-12-11]

41. Post hoc analysis for Friedman's Test (R code). R-statistics blog. URL: https://www.r-statistics.com/2010/02/ post-hoc-analysis-for-friedmans-test-r-code/ [accessed 2020-12-03]

42. White JR, Nagarajan N, Pop M. Statistical methods for detecting differentially abundant features in clinical metagenomic samples. PLoS Comput Biol 2009 Apr;5(4):e1000352 [FREE Full text] [doi: 10.1371/journal.pcbi.1000352] [Medline: 19360128]

43. Zhang X, Yi N. NBZIMM: negative binomial and zero-inflated mixed models, with application to microbiome/metagenomics data analysis. BMC Bioinformatics 2020 Oct 30;21(1):488 [FREE Full text] [doi: 10.1186/s12859-020-03803-z] [Medline: $\underline{33126862]}$

44. Kafadar K, Koehler JR, Venables WN, Ripley BD. Modern applied statistics with S-Plus. Am Stat 1999 Feb;53(1):86-87. [doi: $10.2307 / 2685660$ ]

45. Meyer KA, Kushi LH, Jacobs DR, Slavin J, Sellers TA, Folsom AR. Carbohydrates, dietary fiber, and incident type 2 diabetes in older women. Am J Clin Nutr 2000 Apr;71(4):921-930. [doi: 10.1093/ajcn/71.4.921] [Medline: 10731498]

46. Challacombe CA, Abdel-Aal EM, Seetharaman K, Duizer LM. Influence of phenolic acid content on sensory perception of bread and crackers made from red or white wheat. J Cereal Sci 2012 Sep;56(2):181-188. [doi: 10.1016/j.jcs.2012.03.006]

47. Grafenauer S, Miglioretto C, Solah V, Curtain F. Review of the sensory and physico-chemical properties of red and white wheat: which makes the best whole grain? Foods 2020 Jan 28;9(2):136 [FREE Full text] [doi: 10.3390/foods9020136] [Medline: 32012822]

48. Heiniö R, Noort M, Katina K, Alam S, Sozer N, de Kock H, et al. Sensory characteristics of wholegrain and bran-rich cereal foods - a review. Trends Food Sci Technol 2016 Jan;47:25-38. [doi: 10.1016/j.tifs.2015.11.002]

49. Mithul Aravind S, Wichienchot S, Tsao R, Ramakrishnan S, Chakkaravarthi S. Role of dietary polyphenols on gut microbiota, their metabolites and health benefits. Food Res Int 2021 Apr;142:110189. [doi: 10.1016/j.foodres.2021.110189] [Medline: 33773665]

50. Jansson-Knodell CL, Rubio-Tapia A. The fashionable gluten-free diet-wear with caution. Am J Clin Nutr 2021 Mar 11;113(3):491-492. [doi: 10.1093/ajen/nqaa371] [Medline: $\underline{33515028}$ ]

51. Johnson AJ, Vangay P, Al-Ghalith GA, Hillmann BM, Ward TL, Shields-Cutler RR, Personalized Microbiome Class Students, et al. Daily sampling reveals personalized diet-microbiome associations in humans. Cell Host Microbe 2019 Jun 12;25(6):789-802.e5 [FREE Full text] [doi: 10.1016/j.chom.2019.05.005] [Medline: 31194939]

\section{Abbreviations}

ANOVA: analysis of variance

ELISA: enzyme-linked immunosorbent assay

PCR: polymerase chain reaction

PERMANOVA: permutational multivariate analysis of variance 
Edited by G Eysenbach; submitted 23.03.21; peer-reviewed by L Frame, V Fernandes Davies; comments to author 29.06.21; revised version received 16.07.21; accepted 30.07.21; published 06.10.21

Please cite as:

Kinney GA, Haddad EN, Garrow LS, Ng PKW, Comstock SS

An Intervention With Michigan-Grown Wheat in Healthy Adult Humans to Determine Effect on Gut Microbiota: Protocol for a Crossover Trial

JMIR Res Protoc 2021;10(10):e29046

URL: https://www.researchprotocols.org/2021/10/e29046

doi: $\underline{10.2196 / 29046}$

PMID:

(C) Gigi A Kinney, Eliot N Haddad, Linda S Garrow, Perry K W Ng, Sarah S Comstock. Originally published in JMIR Research Protocols (https://www.researchprotocols.org), 06.10.2021. This is an open-access article distributed under the terms of the Creative Commons Attribution License (https://creativecommons.org/licenses/by/4.0/), which permits unrestricted use, distribution, and reproduction in any medium, provided the original work, first published in JMIR Research Protocols, is properly cited. The complete bibliographic information, a link to the original publication on https://www.researchprotocols.org, as well as this copyright and license information must be included. 